\title{
Applications of Laser-Induced Breakdown Spectroscopy for Soil Characterization, Part II: Review of Elemental Analysis and Soil Classification
}

\author{
Paulino Ribeiro Villas-Boas a ; Marco Aurélio de Menezes Franco ${ }^{\text {b; }}$ Ladislau Martin-Neto a ; \\ Hero T. Gollany ${ }^{\text {; }}$; Debora Marcondes Bastos Pereira Milori ${ }^{\text {a }}$ \\ ${ }^{a}$ Embrapa Instrumentation, São Carlos, SP, Brazil \\ ${ }^{\mathrm{b}}$ Institute of Physics, University of São Paulo, São Paulo, SP, Brazil \\ ${ }^{\mathrm{C}}$ USDA-ARS Soil and Water Conservation Research, Adams, OR, USA
}

*Corresponding Author: Paulino Ribeiro Villas-Boas. E-mail: paulino.villas-boas@embrapa.br Running Title: Review of LIBS use for Soil Elemental Analysis

This article has been accepted for publication and undergone full peer review but has not been through the copyediting, typesetting, pagination and proofreading process which may lead to differences between this version and the Version of Record. Please cite this article as doi: 10.1111/ejss.12889

This article is protected by copyright. All rights reserved. 


\section{Summary}

In-field soil health assessments, including plant nutrients and toxic elements, are needed and could improve the sustainability of agriculture production. Among the available analytical techniques for these analyses, laser-induced breakdown spectroscopy (LIBS) has become one of the most promising techniques for real-time soil analysis at low cost and without the need of reagents. The first part of this two-part review (Part I, Villas-Boas et al., 2019) in this issue focused on the fundamentals of LIBS for soil analysis and its use for soil chemical and physical characterization. Our objectives in this review article (Part II) are to review (i) the main applications of LIBS in the determination of soil carbon (C), nutrients and toxic elements, spatial elemental mapping, and (ii) its use in soil classification. Traditional and more recent techniques will be compared to LIBS, considering their advantages and disadvantages. LIBS is a promising, versatile technique for detecting many elements in soil samples, requires little or no sample preparation, takes only a few seconds per sample, and has a low cost per sample compared to other techniques. However, overcoming matrix effects is a challenge for LIBS applications in soil analysis, since most studies are conducted with limited changes in the matrix. In spite of the limitation of matrix effects, a typical LIBS system has a limit of detection of $0.3,0.6,4,7,10$, 18, 46, and $89 \mathrm{mg} \mathrm{kg}^{-1}$ for Mo, Cu, Mg, Mn, Fe, Zn, K, and Ca, respectively. LIBS holds potential for real-time in-field spatial elemental analysis of soils and practical applications in precision farming with proper calibration. This could lead to immediate diagnoses of 
contaminated soil and inefficient nutrient supplies and facilitate well-informed soil management, increasing agricultural production while minimizing environmental impacts.

Keywords: Plant nutrients, precision agriculture, rhizosphere, soil carbon, soil contamination, soil fertility, SOM, spatial elemental mapping, toxic elements

\section{Highlights}

- LIBS is a fast analytical technique with great potential for elemental mapping of soils.

- Elemental analyses of soil and plants and soil classification by LIBS are reviewed.

- Soil and rhizosphere spatial elemental analyses by LIBS are presented.

- LIBS advantages, limitations, and challenges are discussed for soil elemental analysis. 


\section{Introduction}

Rapid determination of soil elemental composition is important for improving agricultural production and reducing agricultural environmental impacts. Among recent analytical techniques, laser-induced breakdown spectroscopy (LIBS) has become one of the most prominent with great potential for real-time and large-scale soil analyses (Villas-Boas et al., 2019). LIBS has been successfully used to determine the content of soil carbon (C) (Cremers \& Radziemski, 2013; Zorov et al., 2015; Senesi \& Senesi, 2016), macro- and micro-nutrients (Bublitz et al., 2001; Harris et al., 2004; Sallé et al., 2005; Popov et al., 2009; Díaz et al., 2012; Rühlmann et al., 2018), and toxic elements (Wisbrun et al., 1993; Multari et al., 1996; HilbkKortenbruck et al., 2001; Bousquet et al., 2007; Senesi et al., 2009; Dell’Aglio et al., 2011; Zaytsev et al., 2018; Wang et al., 2018).

As stated in Part I of this review (Villas-Boas et al., 2019) in this issue, LIBS holds great potential for soil chemical and physical characterization not only for routine lab work but also for in-field analyses, especially with respect to applications in precision agriculture. In Part I, we also provided an introductory overview on how to use LIBS for soil analysis and presented recent LIBS applications in soil characterization, including soil $\mathrm{pH}$, humification degree of soil organic matter (SOM), and soil texture. In this review, we focus on LIBS use for soil elemental analysis, including soil C, nutrients, toxic elements, and for soil classification. Since LIBS fundamentals were covered in Part I of this review, we will refer the reader to some concepts therein as appropriate. 


\section{Elemental soil analysis}

Traditionally, the elemental composition of a soil sample is obtained by chemical analytical techniques, such as chemical extraction (Bray \& Kurtz, 1945; Olsen et al., 1954; Mehlich, 1984), dry combustion (Yeomans \& Bremner, 1991), and inductively coupled plasma (ICP) or atomic absorption spectroscopy (AAS) (Huang \& Schulte, 1985; Houba et al., 2000; Tüzen, 2003). The first is used for available nutrients, the second for light elements (e.g., hydrogen (H), sulphur (S), nitrogen ( $\mathrm{N}$ ) and $\mathrm{C}$ ), and the third for other elements (about 70), except $\mathrm{C}, \mathrm{H}, \mathrm{O}, \mathrm{N}$ and halogens. Chemical extraction for available nutrients is usually performed by the Mehlich III (Mehlich, 1984), Bray (Bray \& Kurtz, 1945), or Olsen (Olsen et al., 1954) methods, or by their modified versions. The results of these methods are mostly comparable but may differ according to $\mathrm{pH}$, texture, carbonate content, or iron (Fe) content of the soil samples (Wuenscher et al., 2015). Since these methods require reagents and take hours to analyse samples, they are impractical for large-scale soil fertility mapping.

Elemental analysis via dry combustion is the most common technique used for the determination of soil C, but requires sample preparation, consumes argon (Ar) or helium as a carrier gas, and needs standards for H, N, C, and S calibrations (Yeomans \& Bremner, 1991). Thus, such analysis is impractical for large-scale soil C mapping to assess whether a given crop or tillage increases soil C stocks. This is much more critical in farms with large cultivated areas, for example in Brazilian savannah areas (Borghi et al., 2016). 
Inductively coupled plasma (ICP) spectroscopy or atomic absorption spectroscopy (AAS) is generally used for toxic trace element quantification, in which the total content is needed to determine whether a soil is contaminated and the sensitivity requirement is high (e.g., the sensitivity of ICP technique lies in the range of 0.1 to $100 \mu \mathrm{g} \mathrm{m}^{-3}$, Ambushe et al., 2015; Hou et al., 2016). In the case of ICP or AAS analysis, sample preparation is more laborious than for elemental analysis via dry combustion, because samples need to be acidified, which is a meticulous task. Just as with chemical extraction analyses, ICP or AAS analysis requires reagents and is time-consuming, it, therefore, cannot be used for large-scale measurements.

The LIBS analytical process is much simpler than the other techniques and may provide the concentrations of a broad range of elements in a sample with just one measurement, which can enable large-scale mapping of C, nutrients, and toxic element contents. Soils constitute highly intricate matrices, because of their diverse composition and physical structure, which restrict the development of universal calibration models. To overcome such difficulties, researchers have developed models specifically for each soil type with a similar mineral composition to minimize matrix effects. Thus, instead of one universal model for each element, a LIBS system may have a specific model for different soil types. This section covers LIBS calibration models for the quantification of $\mathrm{C}$, nutrients and toxic elements in soil samples. 


\section{Carbon}

Carbon is one of the most studied elements in soil analysis using LIBS (Senesi \& Senesi, 2016), mainly because of concerns about the need to increase soil $\mathrm{C}$ sequestration to mitigate global climate change caused by greenhouse gas emissions (Lal, 2004a; b; Gollany \& Venterea, 2018). Its importance in these areas is due to the fact that $\mathrm{C}$ is the main constituent of SOM, often assumed to be 58\% (Nelson \& Sommers, 1982). Not only does SOM strongly influence biological, chemical and physical soil properties, but also it is generally considered a key soil health indicator (Reeves, 1997). Soil organic matter has an important role in maintaining soil fertility, protecting soil from erosive forces and reducing carbon dioxide $\left(\mathrm{CO}_{2}\right)$ emissions. At the global scale, soil agroecosystems can be a $\mathrm{CO}_{2}$ source or sink (Lal, 2010; Feller et al., 2012), since the rate of soil C storage can be increased by the adoption of specific management practices (Smith et al., 2008; Lal, 2010; Gollany \& Venterea, 2018). However, to estimate the magnitude of soil C stocks, methodological standardization and periodic monitoring must be addressed in long-term field studies. Also, the development of simple, inexpensive and, if possible, in situ soil C quantification methods is of great interest to substitute conventional elemental analysis via dry combustion or classic Walkley \& Black chromic acid wet oxidation methods.

Promising alternatives for rapid soil C quantification have been developed, including inelastic neutron scattering spectroscopy (INS) (Wielopolski et al., 1999, 2003, 2010), near- and mid-infrared diffuse reflectance spectroscopy (NIRS, MIRS, DRIFTS) (McCarty et al., 2002), 
remote sensed imagery (Chen et al., 2000) and LIBS (Senesi \& Senesi, 2016). All of these techniques require little or no sample preparation but have instrumental or procedural limitations. Particularly, INS can analyse large amounts of intact soil samples $\left(0.3 \mathrm{~m}^{3}\right)$ but presents high equipment and transportation costs and requires professionals trained in radiological procedures. Despite its relatively low operational cost, NIRS and MIRS require a large number of samples to calibrate, are affected by sample moisture and carbonate contents and only indirectly measure C content, making it difficult to interpret results. Based on reflectance, remotely sensed imagery can map large areas without the need to collect a sample, but it is restricted to the soil surface and may not correctly estimate soil organic C, because its reflectance can be overlapped by other compounds such as Fe oxides. In addition, remotely sensed imagery cannot be used for soil C sequestration studies, because deep soil layers cannot be assessed.

LIBS may be a viable alternative to overcome the limitations of other techniques, because it takes less than a second to obtain a result, is easy to operate, and can directly measure total soil C (inorganic and organic $\mathrm{C}$ can be indirectly quantified using multivariate methods). The potential advantage of this technique is that it could be used in the field to measure $\mathrm{C}$ in a large number of soil types with temporal and spatial variability. For total C determination with LIBS, a C emission line must be chosen among countless emission lines found in databases (Smith et al., 1995; Kramida et al., 2018); however, only a few are usually used, because the majority have low emission probability (Einstein coefficient). Weak C emission lines, such as at $833.51 \mathrm{~nm}$, can be considered, but are less frequently used, because it requires a means to be intensified, 
such as double-pulse (DP)-LIBS or LIBS with spark excitation (Belkov et al., 2009). The lines most often used for C calibration curves are those at 193.03 and $247.86 \mathrm{~nm}$ (Cremers et al., 2001; Ebinger et al., 2003; Martin et al., 2003, 2010; da Silva et al., 2008; Glumac et al., 2010; Ayyalasomayajula et al., 2012; Nicolodelli et al., 2014; Nguyen et al., 2015) because they are the strongest lines and commonly found in the range 190-1000 nm of LIBS spectrometers. The line at $193.03 \mathrm{~nm}$ is the least used because it is strongly absorbed by atmospheric $\mathrm{O}_{2}$ (Noll, 2012), if the measurement is taken under air atmospheric condition.

Developing a calibration curve for $\mathrm{C}$ concentration in soil samples is not an easy task because of intricate matrix effects. For example, the $\mathrm{C}$ line intensity of two soil samples with the same C concentration can vary considerably with soil texture. To minimize matrix effects, normalization of $\mathrm{C}$ lines with silicon (Si) or aluminium (Al) lines are usually used for the calibration curves, but the concentration of these elements should not vary among the samples analysed (Cremers et al., 2001; Ebinger et al., 2003). Such normalization may not be viable for samples of differing soil types. Another alternative to overcome matrix effects is using multivariate models (Martin et al., 2003; Ayyalasomayajula et al., 2012) which consider the information from other elements, but they are restricted to the LIBS system and sample set used.

Depending on the soil type, $\mathrm{C}$ emission lines may be subject to interference. For soils rich in $\mathrm{Al}$ and $\mathrm{Fe}$, such as most Brazilian soils, the C I lines at $193.03 \mathrm{~nm}$ and $247.86 \mathrm{~nm}$ are prone to interference from the $\mathrm{Al} \mathrm{II} \mathrm{line} \mathrm{at} 193.04 \mathrm{~nm}$, and the Fe I line at $247.98 \mathrm{~nm}$, respectively. Such interference cannot be resolved even with high-resolution spectrometers. To resolve Fe I 
interference at C I line at $247.86 \mathrm{~nm}$, another Fe I line can be used to infer the Fe I contribution of the peak at $247.86 \mathrm{~nm}$ (Bai et al., 2016), thus eliminating Fe interference. For fly ash, the best result was obtained with the Fe I line at $247.98 \mathrm{~nm}$ (Bai et al., 2016). Similarly, Al II interference at C I line at $193.03 \mathrm{~nm}$ can be corrected using the $\mathrm{Al} \mathrm{II} \mathrm{line} \mathrm{at} 193.63 \mathrm{~nm}$ (Nicolodelli et al., 2014). To illustrate this solution for Al II interference (Figure 1), we present below a calibration model for the C I line at $193.03 \mathrm{~nm}$. Most Brazilian soils, including Oxisols and Spodosols, are rich in $\mathrm{Al}$ and $\mathrm{Fe}$, and their emissions overlap $\mathrm{C}$ lines and may compromise the C determination when using LIBS (Figure 2). Oxisol, the most common soil found in Brazil, contains a reasonable amount of $\mathrm{Al}$ and $\mathrm{Fe}$, while Spodosol, found in Amazon, is Fe poor. Since the $\mathrm{C}$ emission line at $247.86 \mathrm{~nm}$ is in a region where the baseline is difficult to determine (Figure 2b), the line at $193.03 \mathrm{~nm}$ was chosen for the quantification of $\mathrm{C}$ in these samples. To remove $\mathrm{Al}$ interference, a model was proposed to subtract the $\mathrm{Al}$ contribution to the $\mathrm{C}$ emission line at $193.03 \mathrm{~nm}$, since the spectrometer could not resolve the ionic Al lines at 193.04 and $193.16 \mathrm{~nm}$. Although in the original work, the Al emission line at $193.56 \mathrm{~nm}$ was assumed to be an atomic $\mathrm{Al}$ line, in this spectral region, $\mathrm{Al}$ II emission line at $193.63 \mathrm{~nm}$ is more likely to be found than the atomic $\mathrm{Al}$ line at $193.56 \mathrm{~nm}$. The contribution of $\mathrm{Al}$ II lines at 193.04 and 193.16 nm was then assumed to be proportional to the intensity of Al II line at $193.63 \mathrm{~nm}$ (Nicolodelli et al., 2014). Therefore, it was assumed that:

$$
C_{C} \propto A_{193.03}-\alpha A_{193.56}
$$


where: $C_{C}$ is the $\mathrm{C}$ concentration; $\alpha$ is the contribution of $\mathrm{Al}$ lines to the peak at $193.03 \mathrm{~nm}$; $A_{193.03}$ is the peak area at $193.03 \mathrm{~nm}$; and $A_{193.56}$ is the peak area at $193.56 \mathrm{~nm}$. However, the peak at $193.03 \mathrm{~nm}$ showed self-absorption, and the linearity between C concentration and the emission line at $193.03 \mathrm{~nm}$ was not observed. Therefore, C concentration was adjusted to the exponential model:

$$
\ln C_{C}=\beta\left(A_{193.03}-\alpha A_{193.56}\right)+\gamma
$$

where: $\beta, \alpha$, and $\gamma$ were constants to be determined by linear regression. The regression resulted in $\alpha=1.25 \pm 0.05$ for the correction of $\mathrm{Al}$ contribution to $\mathrm{C}$ line $193.03 \mathrm{~nm}$, and a Pearson correlation coefficient of 0.91 with a mean error of $19 \%$ (Figure 3). The limit of detection (LOD) calculated was $0.3 \%$.

Another possibility to minimize $\mathrm{Al}$ or Fe interference and matrix effects is by adjusting LIBS parameters. Choosing the right combination of delay time, laser pulse wavelength and energy, and focal length has led to improved quantification models for total C while minimizing Fe interference of the C line at $247.86 \mathrm{~nm}$ and matrix effects (Glumac et al., 2010; Ayyalasomayajula et al., 2012).

\section{Organic and Inorganic C Quantification}

LIBS can also be used to quantify organic and inorganic C, using stoichiometric relations between the elements in the soil samples. The stoichiometric relations between titanium (Ti), Fe, magnesium (Mg), calcium (Ca), sodium $(\mathrm{Na}), \mathrm{Si}$, potassium $(\mathrm{K})$, and $\mathrm{S}$ has been found to be 
useful to discriminate between total, organic, and inorganic C in soil samples (Bricklemyer et al., 2011, 2013; Martin et al., 2013). Since finding these relations is not an easy task, multivariate methods have been used for taking into account large spectral ranges to determine the total, organic and inorganic concentration in soil samples (Bricklemyer et al., 2011, 2013). The results for organic and inorganic $\mathrm{C}$ quantification have not reached the same accuracy and precision as for total C, mainly due to the complex and diverse stoichiometric correlations and matrix effects found in the soil samples (Senesi \& Senesi, 2016).

Recently, LIBS has been successfully applied for total C quantification of various soil types, in many countries producing good correlations $(\mathrm{R}>0.89)$ to reference techniques (See e.g., Senesi \& Senesi, 2016), and with reasonable LOD of $0.3 \mathrm{~g} \mathrm{C} \mathrm{kg}^{-1}$ (Cremers et al., 2001; Nicolodelli et al., 2014). More work is still needed to improve inorganic and organic C quantification in soil samples and to extend the application of LIBS to soil samples of distinct origin and nature, with large variations of organic C (Senesi \& Senesi, 2016).

\section{Plant nutrients}

Soil fertility is essential for healthy plant development since nutrient deficiency can impair plant growth. Typically, soil nutrients are determined by chemical extraction for available macro- and micronutrients (Bray \& Kurtz, 1945; Olsen et al., 1954; Mehlich, 1984), dry combustion for C, H, N, O, and S (Yeomans \& Bremner, 1991), and ICP or AAS for total elemental analysis (Huang \& Schulte, 1985; Houba et al., 2000; Tüzen, 2003). In many cases, 
chemical extraction of specific nutrient species is preferable because it is presumed to measure the content of nutrients available to plants instead of the total. However, all these methods require reagents and take a long time (hours to days) to obtain results, which makes them unfeasible for large-scale measurements. Since LIBS is fast (i.e., each measurement takes less than a minute), it represents a promising solution for large-scale measurement of soil nutrients compared to traditional soil nutrient analyses. Many LIBS applications to quantify nutrients in the soil are reported in the literature (Bublitz et al., 2001; Harris et al., 2004; Sallé et al., 2005; Díaz et al., 2012; Rühlmann et al., 2018). The main results and considerations in measuring macronutrients and micronutrients are presented, including the emission lines mostly used and found in the literature (Table 1).

Among the macronutrients N, P, K, S, Ca, and Mg, the elements N, P, and S are the most difficult to quantify using LIBS. Soil $\mathrm{N}$ cannot be measured using LIBS in atmospheric air because atmospheric $\mathrm{N}_{2}$ participates in the plasma formation, and therefore the proportion of soil $\mathrm{N}$ cannot be estimated. Martin et al. $(2002,2003)$ proposed using a low energy pulse $(23 \mathrm{~mJ}$ at $266 \mathrm{~nm}$ ) and focusing the pulse just below the surface of the sample to avoid atmospheric $\mathrm{N}$ interference and participating in plasma formation. They then supposedly utilized $\mathrm{N}$ ionic lines between 490 and $507 \mathrm{~nm}$ from the sample. However, Harris et al. (2004) proved later that the lines in that spectral range were Ti I rather than N II lines. At 5.33 Pa atmospheric pressure, Harris et al. (2004) succeeded in developing a calibration curve for $\mathrm{N}$ using laser pulse energy of $60 \mathrm{~mJ}$ and the atomic line at $746.83 \mathrm{~nm}$ in sea sand samples with added $\mathrm{N}$ concentration ranging 
from 3.3 to $60 \mathrm{~g} \mathrm{~kg}^{-1}$. Under these conditions, the authors obtained a LOD of $8 \mathrm{~g} \mathrm{~kg}^{-1}$ for $\mathrm{N}$. Dong et al. (2013) optimized laser pulse energy and delay time to quantify $\mathrm{N}$ in a soil sample from a wheat field in China with added $\mathrm{N}$ ranging from 12 to $80 \mathrm{~g} \mathrm{~kg}^{-1}$ under an Ar atmosphere and obtained the best results with $200 \mathrm{~mJ}$ per pulse at $1064 \mathrm{~nm}$, and a delay time of $2 \mu \mathrm{s}$. Further, under an Ar atmosphere, Lu et al. (2013) developed a calibration model for $\mathrm{N}$ using a laser pulse at $1064 \mathrm{~nm}$ with $50 \mathrm{~mJ}$ and a delay time of $1 \mu$ s for 30 soil samples from Chinese farmlands with $\mathrm{N}$ content of 2 to $3.2 \mathrm{~g} \mathrm{~kg}^{-1}$ and obtained $\mathrm{r}^{2}=0.98$ with a mean absolute error of $0.053 \mathrm{~g} \mathrm{~kg}^{-1}$. Even with these successful efforts in finding a calibration curve between $\mathrm{N}$ emission lines and $\mathrm{N}$ concentration in soil samples measured in vacuum or Ar atmosphere, the analysis of a large soil sample set remains challenging, due to matrix effects and LIBS sensitivity. Only a few soil types were considered in those experiments, and matrix effects were negligible, but they will be relevant for large soil sample sets. In addition, LIBS may not be sensitive enough to measure $\mathrm{N}$ concentration in many cropland and pasture soils where $\mathrm{N}$ content can range between 0.6 and $5 \mathrm{~g}$ $\mathrm{kg}^{-1}$ (Bremner, 1996), which is at least an order of magnitude lower than the concentrations used in these experiments.

LIBS may also not be sensitive enough to detect $\mathrm{P}$ and $\mathrm{S}$ unless the LIBS signal is enhanced [See Zorov et al. (2015) for a comprehensive review on methods to enhance LIBS signal], because these elements are nonmetals, are found in mineral soils, and their emission lines are weak. Phosphorus is found in the range of 0.2 to $5 \mathrm{~g} \mathrm{P} \mathrm{kg}^{-1}$ with an average of $0.5 \mathrm{~g} \mathrm{P} \mathrm{kg}^{-1}$ (Lindsay et al., 1989), while $\mathrm{S}$ is found in the range of 0.02 to $0.6 \mathrm{~g} \mathrm{~S} \mathrm{~kg}^{-1}$ in mineral soils 
(Tabatabai, 1996). Considering the P emission lines at 255.3 and 255.5 nm, Díaz et al. (2012) developed calibration curves for total P in a set of commercial soil samples mixed with varying concentrations of two fertilizers in the range of 2 to $38 \mathrm{~g} \mathrm{~kg}^{-1}$ and obtained a LOD of $251 \mathrm{mg} \mathrm{kg}$ ${ }^{1}$. The use of LIBS coupled with a laser-induced fluorescence system in steel samples achieved a LOD of $0.7 \mathrm{mg} \mathrm{P} \mathrm{kg}^{-1}$ (Shen et al., 2009). This may be a possible approach to improve the LOD for soil samples, but the system is very expensive (at least twice the price of a LIBS equipment). For $\mathrm{S}$ in soils, the lowest LOD found was $1.1 \mathrm{~g} \mathrm{~kg}^{-1}$ for Los Alamos soil samples using a laser pulse at $1064 \mathrm{~nm}, 7 \mathrm{~ns}, 40 \mathrm{~mJ}$, and a delay time of $0.5 \mu$ s in a controlled $\mathrm{CO}_{2}$ atmosphere of 933 Pa (7 torr), simulating Mars atmosphere, and considering the ionic line at $545.4 \mathrm{~nm}$ (Radziemski et al., 2005).

Other macronutrients such as $\mathrm{K}, \mathrm{Ca}$, and Mg have strong and detectable emission lines even at low concentrations, and their calibration models are easier to develop than for N, P, and S. A LOD of 46, 89, and $4 \mathrm{mg} \mathrm{kg}^{-1}$ was obtained for $\mathrm{K}$, Ca, and $\mathrm{Mg}$, respectively, using a typical LIBS system with a Nd:YAG laser at 1064 nm, 53 mJ and 10 ns (Díaz et al., 2012). Intense lines are also observed for the copper (Cu), Fe, manganese (Mn), zinc (Zn) and molybdenum (Mo) micronutrients, with lowest LODs of 0.6 (Popov et al., 2014), 10 (Díaz et al., 2012), 7 (Multari et al., 1996), 18 (Popov et al., 2013), and $0.3 \mathrm{mg} \mathrm{kg}^{-1}$ (Popov et al., 2014), respectively.

As with the macronutrients $\mathrm{P}$ and $\mathrm{S}$, the emission lines of the micronutrients boron (B) and chlorine (Cl) are also weak and, therefore, not easily found in LIBS spectra. With typical LIBS systems, B and $\mathrm{Cl}$ are hardly detected. Radziemski et al. (2005) succeeded in quantifying $\mathrm{Cl}$ 
(emission line at $133.6 \mathrm{~nm}$ ) with LOD of $75 \mathrm{~g} \mathrm{~kg}^{-1}$ when studying reduced pressure conditions in a chamber with a vacuum ultraviolet spectral region (100-200 nm). Using a LIBS combined with laser-induced radical fluorescence, Guo et al. (2018) managed to quantify B by boron monoxide (BO) molecular fragment emission at $255.14 \mathrm{~nm}$, with a LOD of $1 \mathrm{~g} \mathrm{~kg}^{-1}$. Almost at the end of the plasma lifetime, atoms begin to recombine and form molecular fragments. At this stage, the emission of molecular fragments can be detected, but are generally very weak and undetectable with usual LIBS systems. More studies are needed to enhance emission line intensities for nutrients such as $\mathrm{P}, \mathrm{S}, \mathrm{B}$, and $\mathrm{Cl}$.

An important limitation for nutrient analysis using LIBS and calibration curves is that the technique can only quantify the total concentration of an element, and cannot on its own estimate the size of the bioavailable concentration of the element for plant or microbial consumption. One solution is to develop multivariate models to quantify available nutrients considering the relation between their emission lines and those of other elements. However, all reviewed studies reported and developed models for total nutrient content; therefore, LIBS potential for available nutrient analysis is yet to be demonstrated. The analysis of nutrients with the LIBS technique has made modest progress since the initial studies. A limited number of studies were found, of which the majority only analysed a few samples, with small variations in the matrices. Reducing the LOD for some nutrients is still a great challenge, especially for $\mathrm{P}$ and $\mathrm{S}$. The $\mathrm{N}$ quantification has not been resolved yet and further controlled atmosphere studies are needed. Solving matrix effects are also a great challenge for nutrient quantification in a large set, as discussed by Rühlmann et 
al. (2018). The potential of the LIBS technique is still unrealised for quantifying available nutrients in soils.

\section{Toxic elements}

Toxic elements, in particular metals, occur naturally in soil and are usually present at low concentration, but may accumulate in urban and agricultural lands due to anthropogenic activities, such as mining, disposal of toxic contaminants (e.g., battery waste and leaded paints), application of fertilizers and animal manure, disposal of sewage sludge, pesticide use, wastewater irrigation, and spillage of petrochemicals (Wuana \& Okieimen, 2011). Excess toxic elements in soils can not only impair crop and livestock production but also contaminate food and cause serious human health complications depending on the amount consumed (Wuana \& Okieimen, 2011). The toxic elements most commonly found at contaminated sites are in order of abundance: lead (Pb) < chromium (Cr) < arsenic (As) $<$ Zn $<$ cadmium $(\mathrm{Cd})<\mathrm{Cu}<$ mercury (Hg) < and nickel (Ni) (Wuana \& Okieimen, 2011). To be considered toxic, an element in soil must have a concentration above a certain threshold (Table 2). The concentration of toxic elements is usually determined by ICP or AAS using aqua regia extractant with microwaveassisted acid digestion with LOD as given in Table 2 (Tóth et al., 2016). However, these techniques may not be applied for large-scale measurements, because they are time-consuming and require reagents. To overcome these issues, LIBS can be a promising alternative due to its potential to detect toxic trace elements in soil samples (Wisbrun et al., 1994; Yamamoto et al., 
1996; Hilbk-Kortenbruck et al., 2001; Popov et al., 2010, 2014; Zaytsev et al., 2018; Wang et al., 2018). In this section, we will present the use of LIBS to detect toxic elements in soil samples.

The LIBS technique was successfully used (i.e., good correspondence with the reference technique, low error, and LOD below the regulatory guideline values) to quantify toxic elements in soils (Wisbrun et al., 1993; Multari et al., 1996; Gornushkin et al., 1997; Lazic et al., 2001; Hilbk-Kortenbruck et al., 2001; Sirven et al., 2006; Bousquet et al., 2007; Kwak et al., 2009; Senesi et al., 2009; Popov et al., 2010, 2014; Dell’Aglio et al., 2011; Barbafieri et al., 2011; Srungaram et al., 2013; Ambushe et al., 2015; Meng et al., 2015, 2017; Khumaeni et al., 2017; Menegatti et al., 2017; Nicolodelli et al., 2018; Yi et al., 2018; Chen et al., 2018; Zaytsev et al., 2018; Akhtar et al., 2018; Gao et al., 2018; Wang et al., 2018). The technique has been more sensitive than the reference technique when optimized or used with signal enhancement methods (Gornushkin et al., 1997; Hilbk-Kortenbruck et al., 2001; Popov et al., 2010, 2014; Meng et al., 2015; Khumaeni et al., 2017; Yi et al., 2018; Akhtar et al., 2018; Gao et al., 2018). However, measuring toxic elements in soil samples is not easy with LIBS, because the intensity of the emission lines of these elements is generally weak (Chen et al., 2018). In addition, the concentration of these elements in soils is usually very low, less than a few $\mu \mathrm{g} \mathrm{g}^{-1}$ (Chen et al., 2018) except when the soil is contaminated. To circumvent this problem or minimize it, the most intense emission lines of these elements are commonly used (Table 3). 
In addition to using more intense lines for each toxic elements, three methods were developed to improve the sensitivity of the LIBS technique (Gornushkin et al., 1997; HilbkKortenbruck et al., 2001; Popov et al., 2010, 2014; Meng et al., 2015, 2017; Khumaeni et al., 2017; Yi et al., 2018; Gao et al., 2018). The first consists of the use of laser-induced fluorescence-assisted LIBS (LIBS-LIF) to amplify the emission line intensity of an element (Gornushkin et al., 1997; Hilbk-Kortenbruck et al., 2001; Nicolodelli et al., 2018; Gao et al., 2018). This method uses a second laser of specific wavelength to increase the population of species on the upper level of the desired transition, thus increasing the emission of this transition. This method obtained good results for $\mathrm{Cd}$, cobalt $(\mathrm{Co})$, lead $(\mathrm{Pb})$ and antimony $(\mathrm{Sb})$. The second method is the physical or magnetic confinement of the plasma, which leads to an increase in plasma lifetime and, consequently, to an increase in the intensity of all emission lines found in the spectrum (Popov et al., 2010; Meng et al., 2015, 2017; Khumaeni et al., 2017; Akhtar et al., 2018). The physical confinement was used with the following elements: As, barium (Ba), Cd, Cr, Cu, Hg, Mn, Ni, Pb, vanadium (V) and Zn (Popov et al., 2010; Meng et al., 2015, 2017; Khumaeni et al., 2017), while the magnetic confinement was used with Cr only (Akhtar et al., 2018). The third method consists of extracting the metals by means of acid and subsequent drying, a process known as phase transformation method, which lasts less than 20 min, according to Yi et al. (2018). With this method, the authors obtained very low LODs of 0.067 and $0.94 \mathrm{mg}$ $\mathrm{kg}^{-1}$ for $\mathrm{Cd}$ and $\mathrm{Pb}$, respectively. 
Matrix effects are also a very significant problem for quantification of toxic elements using LIBS, although it has not been properly addressed in most of the papers reviewed. Most of these papers have used a few samples doped with varying concentrations of the toxic element. Authors have argued that this procedure was done to obtain a calibration set with a reasonable variation of the concentration of the element of interest, as this would not be possible with samples of real soils. The problem with this approach is that the samples used to develop calibration models had little matrix variation and do not represent real soil samples. However, few papers considered a large sample set (Wang et al., 2018) or very distinct soil samples, even from various parts of the world (Ambushe et al., 2015), and managed to minimize the matrix effects. The main methods used for minimizing matrix effects were:

- Normalization by internal reference or by background radiation. The internal reference is an element with the least variation among the samples (e.g., Fe in soil samples; Popov et al., 2014). Background radiation can be calculated by the total plasma intensity (Dell'Aglio et al., 2011), or by the area of a spectral region without peaks (Srungaram et al., 2013) near the emission line of interest.

- Use of multivariate models (Popov et al., 2014; Zaytsev et al., 2018; Wang et al., 2018). This type of model can be linear or nonlinear relations between the element of interest and the elements of the matrix, therefore, minimize matrix effects. 
- Soil classification followed by calibration curve for each class. Bousquet et al. (2007) demonstrated strong matrix effects in the quantification models and suggested classifying the soil samples and constructing a quantification model for each class.

- Phase transformation method (Yi et al., 2018). The solid-liquid-solid transformation method should in principle eliminate the matrix.

- Data processing sequence (Wang et al., 2018); log transformation of the spectrum (normal data transformation), outlier removal by MAD based method, denoising by Wavelet Transform, baseline removal, and multivariate models.

In recent years, the development of the LIBS technique for toxic element analysis has progressed greatly, especially improving signal strength and minimizing matrix effects. Despite all this progress, developing quantification models is still necessary for large sample sets of samples (>100) with various compositions (e.g., different types of soils with varied textures). In addition, the direct use of the technique in the field (Yamamoto et al., 1996; Meng et al., 2017) is still underexplored, even for qualitative or semi-quantitative measurements. The direct use in the field will have other problems, such as dust, soil moisture, organic or inorganic wastes that are not part of the soil and particle size, among others, which will need further studies. 


\section{Spatial Elemental Mapping of Root and Rhizosphere}

An emerging field with high potential for LIBS is the rhizosphere spatial elemental mapping. The technique has been successfully applied to map silver (Ag) and $\mathrm{Cu}$ in the crosssections of root tissues of fava bean (Vicia faba), using double-pulse geometry (Krajcarová et al., 2017). The root samples of fava bean, grown in solutions of these elements for 7 days, were cut into $40 \mu \mathrm{m}$ thick cross-sections and then analysed by LIBS with a spatial resolution of $50 \mu \mathrm{m}$. Using the Ag line at $328.07 \mathrm{~nm}$ and $\mathrm{Cu}$ line at $324.75 \mathrm{~nm}$, a 2D raster map of these elements was created (Figure 4). This type of analysis can be used to study plant physiology and ecotoxicology with good precision.

In another study, Ilhardt et al. (2019) used a single LIBS pulse to study plant rhizospheres, a highly dynamic and chemically heterogeneous environment where strong interactions occur between root and soil, and there is a proliferation of microorganisms. In this study, switchgrass (Panicum virgatum) was grown with 17 macro- and micronutrients in a sandy loam Alfisol, and matrix elements were mapped with a spatial resolution of $100 \mu \mathrm{m}$. The technique was capable of detecting and imaging elements with concentrations in the range of $0.01 \mu \mathrm{g} \mathrm{g}^{-1}$ to $20.00 \mu \mathrm{g} \mathrm{g}^{-1}$. These results emphasize potential LIBS applications to studies of soil-plant interactions. Thus, the precision of LIBS spatial measurements together with an effective imaging system can be a good tool for a better understanding of soil-plant interactions to improve crop production. This emerging field could impact the studies of biogeochemical nutrient cycles and help with environmental remediation of contaminated sites. 


\section{Soil Classification}

Accurate soil classification is of extreme importance for agriculture, since complex physical and chemical characteristics, such as texture, cation availability and quantity of organic matter, are crucial for the productivity of a given crop. Usually, soils are classified after an extensive evaluation of numerous attributes, such as colours that indicate oxidation and reduction, soil depth and water table fluctuation, horizons or cohesive or compacted layers, rooting depth and biological activity along the soil profile. Soil classification is an activity that requires an investment of time, resource, and, ultimately, can result in a lot of uncertainty in data interpretation.

To facilitate the soil classification process, many efforts have been made to relate soil type to spectral data, such as those obtained by ICP (Yanai et al., 2012), NIR (Viscarra Rossel et al., 2016), and LIBS (Pontes et al., 2009; Yu et al., 2016). These techniques are all based on the same principle: the soil type is related to the chemical composition of the rocks from which the soil originated. The difference between the techniques is the type of information each evaluates. While ICP and LIBS relate the elemental composition to the soil type, NIR does the same with the molecular composition. Of the three techniques, ICP is the least feasible because it measures the concentration of one element at a time, and the elements important for classification are not known beforehand. NIR spectroscopy is rapid, but the spectrum obtained has few absorption bands, which may limit the accuracy of the technique. The LIBS technique is also fast and has a much greater diversity in emission peaks compared to NIR spectroscopy. Thus, among these 
techniques, LIBS is the one that has the greatest potential to be used for soil classification and identification of elements that have a relation to the soil type and origin.

Despite the potential of LIBS to classify soils, only two studies have been reported (Pontes et al., 2009; Yu et al., 2016). Pontes et al. (2009) developed a model to classify three soil types, Latossolo, Nitossolo, and Argissolo (Brazilian soil types) based on linear discriminant analysis with variable selection and obtained a success rate of $72 \%$ in the cross-validation. Similarly, $\mathrm{Yu}$ et al. (2016) obtained a success rate of 100\% using least-squares support vector machine (LSSVM) technique to distinguish six soil classes: black, sandy, saline-alkali, and loess soils; and two sediments from various Chinese regions. In the second study, the authors also showed that the elements $\mathrm{Al}, \mathrm{Fe}, \mathrm{Mg}, \mathrm{Ca}, \mathrm{Na}, \mathrm{K}$, and $\mathrm{Si}$ contributed the most to discriminate among the soil types analysed.

When analysing soil samples, an interesting aspect is the relation of the soil type to matrix effects (El Haddad et al., 2014). Since the soil type is related to the chemical composition, soil samples of the same type tend to have similar concentrations of the main constituent elements. Thus, samples of the same type tend to undergo the same matrix effects. This is the reason why soil classification using LIBS has the highest success rates. Based on this finding, one way of minimizing the matrix effects in calibration models is to subdivide the sample set into soil classes and develop a model for each class. Without the subdivision, Bousquet et al. (2007) showed that a calibration curve for Cr developed for kaolinite samples did not predict satisfactorily the $\mathrm{Cr}$ content of samples from other matrices. The authors suggested that a sample 
classification should be performed prior to quantitative analysis. Further work is needed to validate this concept.

\section{Concluding remarks}

LIBS is an emerging analytical technique that is gaining popularity because of its ability to detect a broad range of elements, while requiring little or no sample preparation or reagents, and taking only a few seconds per sample to analyse. It uses a high-energy laser pulse to create transient plasma, and its emission reveals the elements in the sample and these elements can be identified and quantified easily. Currently, LIBS is already used in quantification of trace elements in the production of steel and in coal mines and is embedded in standalone systems such as that installed by NASA in the Curiosity Rover to explore soil on Mars, and those made portable for in-field analysis such as handheld devices.

There is increasing interest in the use of LIBS in agricultural systems, especially for soil analysis, including studies involving C, nutrients, and toxic element quantification. We discussed LIBS for those uses in this article of a two-part review. In Part I of this review (this issue) we presented recent studies on evaluation of soil chemical (i.e., $\mathrm{pH}$ and the humification degree of SOM), and physical properties (i.e., soil texture). Among the elemental quantitative analyses, C and toxic elements had the largest number of studies, followed by nutrients. Analysis of C has advanced greatly in recent years, with solutions for the interference of $\mathrm{Al}$ and Fe lines, and with models for quantification of organic and inorganic C. Much progress has also been made to 
improve LIBS sensitivity (i.e., LOD reduction) for the quantification of trace elements with signal-enhancement techniques. Advances in nutrient quantification were more modest, with many open challenges, such as reducing LOD for P, S and minor micronutrients, and estimating nutrient availability. Despite advances in these applications, the problem of matrix effects is still the most challenging, since most studies did not consider large sets of samples with varying origins and textures. This remains the biggest challenge facing LIBS applications for soil analysis in the future.

Once these challenges can be overcome, the LIBS technique holds the potential to become an important soil analysis tool for soil scientists, agricultural producers, agricultural companies, environmental regulatory agencies, among others. Soil scientists working jointly with LIBS engineers are endeavouring to make the technique more stable, robust and universal to assess various soil properties. Subsequently, LIBS may soon be integrated into tractor implements or embedded in rovers to map a field in real-time and as demanded by precision farming and currently by digital agriculture. This will help producers obtain regular and readily available information to increase production while minimizing environmental impacts.

\section{Data availability statement}

Data sharing is not applicable to this article as no new data were created or analysed in this study. 


\section{Acknowledgments}

This work was supported by CNPq (grants 312647/2018-2, 153993/2017-0 and 403405/2013-0) and FAPESP (grant 2013/07276-1).

The authors declare no conflict of interest.

\section{References}

Akhtar, M., Jabbar, A., Mehmood, S., Ahmed, N., Ahmed, R. \& Baig, M.A. 2018. Magnetic field enhanced detection of heavy metals in soil using laser induced breakdown spectroscopy. Spectrochimica Acta Part B: Atomic Spectroscopy, 148, 143-151.

Ambushe, A.A., du Plessis, A. \& McCrindle, R.I. 2015. Laser-induced breakdown spectroscopy and inductively coupled plasma-mass spectrometry for determination of $\mathrm{Cr}$ in soils from Brits District, South Africa. Bulletin of the Chemical Society of Ethiopia, 29, 357-366.

Ayyalasomayajula, K.K., Yu-Yueh, F., Singh, J.P., Mcintyre, D.L. \& Jain, J. 2012. Application of laser-induced breakdown spectroscopy for total carbon quantification in soil samples. Applied optics, 51, B149-54.

Bai, K., Yao, S., Lu, J., Zhao, J., Xu, J. \& Lu, Z. 2016. Correction of C-Fe line interference for the measurement of unburned carbon in fly ash by LIBS. Journal of Analytical Atomic Spectrometry, 31, 2418-2426.

Barbafieri, M., Pini, R., Ciucci, A. \& Tassi, E. 2011. Field assessment of Pb in contaminated soils and in leaf mustard (Brassica juncea): the LIBS technique. Chemistry and Ecology, 27, 161-169.

Belkov, M.V., Burakov, V.S., De Giacomo, A., Kiris, V.V., Raikov, S.N. \& Tarasenko, N.V. 2009. Comparison of two laser-induced breakdown spectroscopy techniques for total carbon measurement in soils. Spectrochimica Acta Part B: Atomic Spectroscopy, 64, 899-904.

Borghi, E., Avanzi, J.C., Bortolon, L., Luchiari Junior, A. \& Bortolon, E.S.O. 2016. Adoption 
and Use of Precision Agriculture in Brazil: Perception of Growers and Service Dealership. Journal of Agricultural Science, 8, 89.

Bousquet, B., Sirven, J.-B. \& Canioni, L. 2007. Towards quantitative laser-induced breakdown spectroscopy analysis of soil samples. Spectrochimica Acta Part B: Atomic Spectroscopy, 62, 1582-1589.

Bray, R.H. \& Kurtz, L.T. 1945. Determination of total, organic and available form of phosphorus in soils. Soil Science, $\mathbf{5 9}$.

Bremner, J.M. 1996. Nitrogen - total. In: Methods of Soil Analysis. Part 3. Chemical Methods (ed. Sparks, D.L.), pp. 1085-1121. SSSA Book Series No. 5. SSSA and ASA, Madison, WI.

Bricklemyer, R.S., Brown, D.J., Barefield, J.E. \& Clegg, S.M. 2011. Intact Soil Core Total, Inorganic, and Organic Carbon Measurement Using Laser-Induced Breakdown Spectroscopy. Soil Science Society of America Journal, 75, 1006.

Bricklemyer, R.S., Brown, D.J., Turk, P.J. \& Clegg, S.M. 2013. Improved Intact Soil-Core Carbon Determination Applying Regression Shrinkage and Variable Selection Techniques to Complete Spectrum Laser-Induced Breakdown Spectroscopy (LIBS). Applied Spectroscopy, 67, 1185-1199.

Bublitz, J., Dölle, C., Schade, W., Hartmann, A. \& Horn, R. 2001. Laser-induced breakdown spectroscopy for soil diagnostics. European Journal of Soil Science, 52, 305-312.

Chen, C.P., Hei, L., Yu, S.C., Chen, W.L. \& Cai, M.X. 2018. Application of Laser Induced Breakdown Spectroscopy in Soil Element Analysis of Watershed. In: MATEC Web of Conferences, p. 1114. EDP Sciences.

Chen, F., Kissel, D.E., West, L.T. \& Adkins, W. 2000. Field-scale mapping of surface soil organic carbon using remotely sensed imagery. Soil Science Society of America Journal, 64, 746-753.

Cremers, D.A., Ebinger, M.H., Breshears, D.D., Unkefer, P.J., Kammerdiener, S.A., Ferris, M.J., Catlett, K.M. \& Brown, J.R. 2001. Measuring Total Soil Carbon with Laser-Induced 
Breakdown Spectroscopy (LIBS). Journal of Environmental Quality, 30, 2202-2206.

Cremers, D.A. \& Radziemski, L.J. 2013. Handbook of Laser-Induced Breakdown Spectroscopy. John Wiley \& Sons Ltd, Oxford, UK.

Dell’Aglio, M., Gaudiuso, R., Senesi, G.S., De Giacomo, A., Zaccone, C., Miano, T.M. \& De Pascale, O. 2011. Monitoring of $\mathrm{Cr}, \mathrm{Cu}, \mathrm{Pb}, \mathrm{V}$ and $\mathrm{Zn}$ in polluted soils by laser induced breakdown spectroscopy (LIBS). Journal of Environmental Monitoring, 13, 1422-1426.

Díaz, D., Hahn, D.W. \& Molina, A. 2012. Evaluation of laser-induced breakdown spectroscopy (LIBS) as a measurement technique for evaluation of total elemental concentration in soils. Applied Spectroscopy, 66, 99-106.

Dong, D.M., Zhao, C.J., Zheng, W.G., Zhao, X.D. \& Jiao, L.Z. 2013. Spectral Characterization of Nitrogen in Farmland Soil by Laser-Induced Breakdown Spectroscopy. Spectroscopy Letters, 46, 421-426.

Ebinger, M.H., Norfleet, M.L., Breshears, D.D., Cremers, D.A., Ferris, M.J., Unkefer, P.J., Lamb, M.S., Goddard, K.L. \& Meyer, C.W. 2003. Extending the Applicability of LaserInduced Breakdown Spectroscopy for Total Soil Carbon Measurement. Soil Science Society of America Journal, 67, 1616-1619.

Feller, C., Blanchart, E., Bernoux, M., Lal, R. \& Manlay, R. 2012. Soil fertility concepts over the past two centuries: the importance attributed to soil organic matter in developed and developing countries. Archives of Agronomy and Soil Science, 58, S3-S21.

Gao, P., Yang, P., Zhou, R., Ma, S., Zhang, W., Hao, Z., Tang, S., Li, X. \& Zeng, X. 2018. Determination of antimony in soil using laser-induced breakdown spectroscopy assisted with laser-induced fluorescence. Applied Optics, 57, 8942.

Glumac, N.G., Dong, W.K. \& Jarrell, W.M. 2010. Quantitative Analysis of Soil Organic Carbon Using Laser-Induced Breakdown Spectroscopy: An Improved Method. Soil Science Society of America Journal, 74, 1922.

Gollany, H.T. \& Venterea, R.T. 2018. Measurements and Models to Identify Agroecosystem Practices That Enhance Soil Organic Carbon under Changing Climate. Journal of 
Environmental Quality, 47, 579-587.

Gornushkin, I.B., Kim, J.E., Smith, B.W., Baker, S.A. \& Winefordner, J.D. 1997. Determination of Cobalt in Soil, Steel, and Graphite Using Excited-State Laser Fluorescence Induced in a Laser Spark. Applied Spectroscopy, 51, 1055-1059.

Guo, L.B., Zhu, Z.H., Li, J.M., Tang, Y., Tang, S.S., Hao, Z.Q., Li, X.Y., Lu, Y.F. \& Zeng, X.Y. 2018. Determination of boron with molecular emission using laser-induced breakdown spectroscopy combined with laser-induced radical fluorescence. Optics Express, 26, 26342642.

El Haddad, J., Bruyère, D., Ismaël, A., Gallou, G., Laperche, V., Michel, K., Canioni, L. \& Bousquet, B. 2014. Application of a series of artificial neural networks to on-site quantitative analysis of lead into real soil samples by laser induced breakdown spectroscopy. Spectrochimica Acta Part B: Atomic Spectroscopy, 97, 57-64.

Harris, R.D., Cremers, D. a, Ebinger, M.H. \& Bluhm, B.K. 2004. Determination of nitrogen in sand using laser-induced breakdown spectroscopy. Applied Spectroscopy, 58, 770-5.

Hilbk-Kortenbruck, F., Noll, R., Wintjens, P., Falk, H. \& Becker, C. 2001. Analysis of heavy metals in soils using laser-induced breakdown spectrometry combined with laser-induced fluorescence. Spectrochimica Acta Part B: Atomic Spectroscopy, 56, 933-945.

Hou, X., Amais, R.S., Jones, B.T. \& Donati, G.L. 2016. Inductively Coupled Plasma Optical Emission Spectrometry. In: Encyclopedia of Analytical Chemistry (ed. Meyers, R.A.).

Houba, V.J.G., Temminghoff, E.J.M., Gaikhorst, G.A. \& van Vark, W. 2000. Soil analysis procedures using $0.01 \mathrm{M}$ calcium chloride as extraction reagent. Communications in Soil Science and Plant Analysis, 31, 1299-1396.

Huang, C.L. \& Schulte, E.E. 1985. Digestion of plant tissue for analysis by ICP emission spectroscopy. Communications in Soil Science and Plant Analysis, 16, 943-958.

Ilhardt, P.D., Nuñez, J.R., Denis, E.H., Rosnow, J.J., Krogstad, E.J., Renslow, R.S. \& Moran, J.J. 2019. High-resolution elemental mapping of the root-rhizosphere-soil continuum using laser-induced breakdown spectroscopy (LIBS). Soil Biology and Biochemistry, 131, 119- 
132.

Khumaeni, A., Tani, M., Kurihara, K., Kagawa, K. \& Niki, H. 2017. Coarse Metal PowderAssisted pulsed CO2 Laser-induced Breakdown Spectroscopy for the Direct Determination of Heavy Metals in Soil. Analytical Letters, 50, 1992-1999.

Krajcarová, L., Novotný, K., Kummerová, M., Dubová, J., Gloser, V. \& Kaiser, J. 2017. Mapping of the spatial distribution of silver nanoparticles in root tissues of Vicia faba by laser-induced breakdown spectroscopy (LIBS). Talanta, 173, 28-35.

Kramida, A., Ralchenko, Y., Reader, J. \& NIST ASD Team. 2018. NIST Atomic Spectra Database (version 5.5.3), [Online]. (At: https://physics.nist.gov/asd. Accessed: 22/3/2018).

Kwak, J., Lenth, C., Salb, C., Ko, E.-J., Kim, K.-W. \& Park, K. 2009. Quantitative analysis of arsenic in mine tailing soils using double pulse-laser induced breakdown spectroscopy. Spectrochimica Acta Part B: Atomic Spectroscopy, 64, 1105-1110.

Lal, R. 2004a. Soil carbon sequestration impacts on global climate change and food security. Science (New York, N.Y.), 304, 1623-7.

Lal, R. 2004b. Soil carbon sequestration to mitigate climate change. Geoderma, 123, 1-22.

Lal, R. 2010. Managing Soils and Ecosystems for Mitigating Anthropogenic Carbon Emissions and Advancing Global Food Security. BioScience, 60, 708-721.

Lazic, V., Barbini, R., Colao, F., Fantoni, R. \& Palucci, A. 2001. Self-absorption model in quantitative laser induced breakdown spectroscopy measurements on soils and sediments. Spectrochimica Acta Part B: Atomic Spectroscopy, 56, 807-820.

Lindsay, W.L., Vlek, P.L.G. \& Chien, S.H. 1989. Phosphate minerals. In: Minerals in Soil Environments (eds. Dixon, J.B. \& Weed, S.B.), pp. 1089-1130. 2nd Editio. SSSA Book Series No. 1. SSSA, Madison, WI.

Lu, C., Wang, L., Hu, H., Zhuang, Z., Wang, Y., Wang, R. \& Song, L. 2013. Analysis of total nitrogen and total phosphorus in soil using laser-induced breakdownspectroscopy. Chinese Optics Letters, 11, 53004.

Martin, M.Z., Labbé, N., André, N., Wullschleger, S.D., Harris, R.D. \& Ebinger, M.H. 2010. 
Novel Multivariate Analysis for Soil Carbon Measurements Using Laser-Induced Breakdown Spectroscopy. Soil Science Society of America Journal, 74, 87.

Martin, M.Z., Mayes, M.A., Heal, K.R., Brice, D.J. \& Wullschleger, S.D. 2013. Investigation of laser-induced breakdown spectroscopy and multivariate analysis for differentiating inorganic and organic C in a variety of soils. Spectrochimica Acta - Part B Atomic Spectroscopy, 87.

Martin, M.Z., Wullschleger, S.D., Garten, C.T. \& Palumbo, A. V. 2003. Laser-induced breakdown spectroscopy for the environmental determination of total carbon and nitrogen in soils. Applied optics, 42, 2072-2077.

Martin, M.Z., Wullschleger, S., Jr, C.G. \& Garten, C. 2002. Laser-induced breakdown spectroscopy for environmental monitoring of soil carbon and nitrogen. In: Advanced Environmental Sensing Technology II, pp. 188-196. International Society for Optics and Photonics.

McCarty, G.W., Reeves, J.B., Reeves, V.B., Follett, R.F. \& Kimble, J.M. 2002. Mid-Infrared and Near-Infrared Diffuse Reflectance Spectroscopy for Soil Carbon Measurement. Soil Science Society of America Journal, 66, 640-646.

Mehlich, A. 1984. Mehlich 3 soil test extractant: A modification of Mehlich 2 extractant. Communications in Soil Science and Plant Analysis, 15, 1409-1416.

Menegatti, C.R., Nicolodelli, G., Senesi, G.S., da Silva, O.A., Filho, H.J.I., Villas Boas, P.R., Marangoni, B.S. \& Milori, D.M.B.P. 2017. Semiquantitative analysis of mercury in landfill leachates using double-pulse laser-induced breakdown spectroscopy. Applied Optics, 56, 3730-3735.

Meng, D., Zhao, N., Ma, M., Fang, L., Gu, Y., Jia, Y., Liu, J. \& Liu, W. 2017. Application of a mobile laser-induced breakdown spectroscopy system to detect heavy metal elements in soil. Applied Optics, 56, 5204.

Meng, D., Zhao, N., Ma, M., Wang, Y., Hu, L., Yu, Y., Fang, L. \& Liu, W. 2015. Heavy Metal Detection in Soils by Laser Induced Breakdown Spectroscopy Using Hemispherical Spatial 
Confinement. Plasma Science and Technology, 17, 632-637.

Multari, R.A., Foster, L.E., Cremers, D.A. \& Ferris, M.J. 1996. Effect of Sampling Geometry on Elemental Emissions in Laser-Induced Breakdown Spectroscopy. Applied Spectroscopy, 50, 1483-1499.

Nelson, D.W. \& Sommers, L.E. 1982. Total Carbon, Organic Carbon, and Organic Matter. In: Methods of Soil Analysis. Part 2. Chemical and Microbiological Properties (eds. Page, A.L., Miller, R.H. \& Keeney, D.R.), pp. 539-579. 2nd ed. American Society of Agronomy, Madison, Wis.

Nguyen, H.V.-M., Moon, S.-J. \& Choi, J.H. 2015. Improving the application of laser-induced breakdown spectroscopy for the determination of total carbon in soils. Environmental Monitoring and Assessment, 187, 28.

Nicolodelli, G., Marangoni, B.S., Cabral, J.S., Villas-Boas, P.R., Senesi, G.S., Dos Santos, C.H., Romano, R.A., Segnini, A., Lucas, Y., Montes, C.R. \& Milori, D.M.B.P. 2014.

Quantification of total carbon in soil using laser-induced breakdown spectroscopy: a method to correct interference lines. Applied optics, 53, 2170-2176.

Nicolodelli, G., Villas-Boas, P.R., Menegatti, C.R., Senesi, G.S., Magalhães, D. V, Souza, D. de, Milori, D.M.B.P. \& Marangoni, B.S. 2018. Determination of Pb in soils by double-pulse laser-induced breakdown spectroscopy assisted by continuum wave-diode laser-induced fluorescence. Applied Optics, 57, 8366-8372.

Noll, R. 2012. Laser-Induced Breakdown Spectroscopy: Fundamentals and Applications. Springer Science \& Business Media.

Olsen, S.R., Cole, C.V., Watanabe, F.S. \& Dean, L.A. 1954. Estimation of available phosphorus in soils by extraction with sodium bicarbonate. Washington, DC.

Pontes, M.J.C., Cortez, J., Galvão, R.K.H., Pasquini, C., Araújo, M.C.U., Coelho, R.M., Chiba, M.K., De Abreu, M.F. \& Madari, B.E. 2009. Classification of Brazilian soils by using LIBS and variable selection in the wavelet domain. Analytica Chimica Acta, 642, 12-18.

Popov, A.M., Colao, F. \& Fantoni, R. 2010. Spatial confinement of laser-induced plasma to 
enhance LIBS sensitivity for trace elements determination in soils. Journal of Analytical Atomic Spectrometry, 25, 837-848.

Popov, A.M., Kozhnov, M.O., Labutin, T.A., Zaytsev, S.M., Drozdova, A.N. \& Mityurev, N.A. 2013. Rapid determination of zinc in soils by laser-induced breakdown spectroscopy. Technical Physics Letters, 39, 81-83.

Popov, A.M., Labutin, T.A., Zaytsev, S.M., Seliverstova, I. V., Zorov, N.B., Kal’ko, I.A., Sidorina, Y.N., Bugaev, I.A. \& Nikolaev, Y.N. 2014. Determination of Ag, Cu, Mo and Pb in soils and ores by laser-induced breakdown spectrometry. J. Anal. At. Spectrom., 29, 1925-1933.

Popov, A.M., Labutin, T.A. \& Zorov, N.B. 2009. Application of Laser-Induced Breakdown Spectrometry for analysis of environmental and industrial materials. Moscow University Chemistry Bulletin, 64, 366-377.

Radziemski, L., Cremers, D.A., Benelli, K., Khoo, C. \& Harris, R.D. 2005. Use of the vacuum ultraviolet spectral region for laser-induced breakdown spectroscopy-based Martian geology and exploration. Spectrochimica Acta Part B: Atomic Spectroscopy, 60, 237-248.

Reeves, D.W. 1997. The role of soil organic matter in maintaining soil quality in continuous cropping systems. Soil and Tillage Research, 43, 131-167.

Rühlmann, M., Büchele, D., Ostermann, M., Bald, I. \& Schmid, T. 2018. Challenges in the quantification of nutrients in soils using laser-induced breakdown spectroscopy - A case study with calcium. Spectrochimica Acta Part B: Atomic Spectroscopy, 146, 115-121.

Sallé, B., Cremers, D.A., Maurice, S., Wiens, R.C. \& Fichet, P. 2005. Evaluation of a compact spectrograph for in-situ and stand-off Laser-Induced Breakdown Spectroscopy analyses of geological samples on Mars missions. Spectrochimica Acta Part B: Atomic Spectroscopy, 60, 805-815.

Senesi, G.S., Dell’Aglio, M., Gaudiuso, R., De Giacomo, A., Zaccone, C., De Pascale, O., Miano, T.M. \& Capitelli, M. 2009. Heavy metal concentrations in soils as determined by laser-induced breakdown spectroscopy (\{LIBS $\})$, with special emphasis on chromium. 
Environmental research, 109, 413-420.

Senesi, G.S. \& Senesi, N. 2016. Laser-induced breakdown spectroscopy (LIBS) to measure quantitatively soil carbon with emphasis on soil organic carbon. A review. Analytica Chimica Acta, 938, 7-17.

Shen, X.K., Wang, H., Xie, Z.Q., Gao, Y., Ling, H. \& Lu, Y.F. 2009. Detection of trace phosphorus in steel using laser-induced breakdown spectroscopy combined with laserinduced fluorescence. Applied optics, 48, 2551-2558.

da Silva, R.M., Milori, D.M.B.P., Ferreira, E.C., Ferreira, E.J., Krug, F.J. \& Martin-Neto, L. 2008. Total carbon measurement in whole tropical soil sample. Spectrochimica Acta Part B: Atomic Spectroscopy, 63, 1221-1224.

Sirven, J.-B., Bousquet, B., Canioni, L., Sarger, L., Tellier, S., Potin-Gautier, M. \& Le Hecho, I. 2006. Qualitative and quantitative investigation of chromium-polluted soils by laserinduced breakdown spectroscopy combined with neural networks analysis. Analytical and bioanalytical chemistry, 385, 256-62.

Smith, P., Fang, C., Dawson, J.J.C. \& Moncrieff, J.B. 2008. Impact of Global Warming on Soil Organic Carbon. Advances in Agronomy, 97, 1-43.

Smith, P.L., Heise, C., Esmond, J.R. \& Kurucz, R.L. 1995. Atomic spectral line database, built from atomic data files from R.L. Kurucz' CD-ROM 23. (At: http://www.pmp.unihannover.de/cgi-bin/ssi/test/kurucz/sekur.html. ).

Srungaram, P.K., Ayyalasomayajula, K.K., Yu-Yueh, F. \& Singh, J.P. 2013. Comparison of laser induced breakdown spectroscopy and spark induced breakdown spectroscopy for determination of mercury in soils. Spectrochimica Acta Part B: Atomic Spectroscopy, 87, 108-113.

Tabatabai, M.A. 1996. Sulfur. In: Methods of Soil Analysis. Part 3. Chemical Methods (ed. Sparks, D.L.), pp. 920-960. SSSA Book Series No. 5. SSSA and ASA, Madison, WI.

Tóth, G., Hermann, T., Da Silva, M.R. \& Montanarella, L. 2016. Heavy metals in agricultural soils of the European Union with implications for food safety. Environment International, 
88, 299-309.

Tüzen, M. 2003. Determination of heavy metals in soil, mushroom and plant samples by atomic absorption spectrometry. Microchemical Journal, 74, 289-297.

Villas-Boas, P.R., Franco, M.A. de M., Gollany, H.T., Martin-Neto, L. \& Milori, D.M.B.P. 2019. Applications of Laser-Induced Breakdown Spectroscopy for Soil Characterization, Part I: Review of Fundamentals and Chemical and Physical Properties.

Viscarra Rossel, R.A., Behrens, T., Ben-Dor, E., Brown, D.J., Demattê, J.A.M., Shepherd, K.D., Shi, Z., Stenberg, B., Stevens, A., Adamchuk, V., Aïchi, H., Barthès, B.G., Bartholomeus, H.M., Bayer, A.D., Bernoux, M., Böttcher, K., Brodský, L., Du, C.W., Chappell, A., Fouad, Y., Genot, V., Gomez, C., Grunwald, S., Gubler, A., Guerrero, C., Hedley, C.B., Knadel, M., Morrás, H.J.M., Nocita, M., Ramirez-Lopez, L., Roudier, P., Campos, E.M.R., Sanborn, P., Sellitto, V.M., Sudduth, K.A., Rawlins, B.G., Walter, C., Winowiecki, L.A., Hong, S.Y. \& Ji, W. 2016. A global spectral library to characterize the world's soil. Earth-Science Reviews, 155, 198-230.

Wang, T., He, M., Shen, T., Liu, F., He, Y., Liu, X. \& Qiu, Z. 2018. Multi-element analysis of heavy metal content in soils using laser-induced breakdown spectroscopy: A case study in eastern China. Spectrochimica Acta Part B: Atomic Spectroscopy, 149, 300-312.

Wielopolski, L., Mitra, S., Hendrey, G., Rogers, H., Torbert, A. \& Prior, S. 2003. Nondestructive in situ soil carbon analysis: principle and results. In: National Energy Technology Lab C Sequestration Symposium, pp. 5-8. United States.

Wielopolski, L., Orion, I. \& Hendrey, G. 1999. Soil carbon measurements using inelastic neutron scattering. In: 1999 IEEE Nuclear Science Symposium. Conference Record. 1999 Nuclear Science Symposium and Medical Imaging Conference (Cat. No.99CH37019), pp. 510-511 vol.1.

Wielopolski, L., Yanai, R.D., Levine, C.R., Mitra, S. \& Vadeboncoeur, M.A. 2010. Rapid, nondestructive carbon analysis of forest soils using neutron-induced gamma-ray spectroscopy. Forest Ecology and Management, 260, 1132-1137. 
Wisbrun, R.W., Schechter, I., Niessner, R. \& Schroeder, H. 1993. Laser-induced breakdown spectroscopy for detection of heavy metals in environmental samples. In: Proc.SPIE.

Wisbrun, R., Schechter, I., Niessner, R., Schroeder, H., Kompa, K.L., Schröder, H. \& Kompa, K.L. 1994. Detector for Trace Elemental Analysis of Solid Environmental Samples by Laser Plasma Spectroscopy. Analytical Chemistry, 66, 2964-2975.

Wuana, R.A. \& Okieimen, F.E. 2011. Heavy Metals in Contaminated Soils: A Review of Sources, Chemistry, Risks and Best Available Strategies for Remediation. ISRN Ecology, 2011, 1-20.

Wuenscher, R., Unterfrauner, H., Peticzka, R. \& Zehetner, F. 2015. A comparison of 14 soil phosphorus extraction methods applied to 50 agricultural soils from Central Europe. Plant, Soil and Environment, 61, 86-96.

Yamamoto, K.Y., Cremers, D.A., Ferris, M.J. \& Foster, L.E. 1996. Detection of Metals in the Environment Using a Portable Laser-Induced Breakdown Spectroscopy Instrument. Applied Spectroscopy, 50, 222-233.

Yanai, J., Okada, T. \& Yamada, H. 2012. Elemental composition of agricultural soils in Japan in relation to soil type, land use and region. Soil Science and Plant Nutrition, 58, 1-10.

Yeomans, J.C. \& Bremner, J.M. 1991. Carbon and nitrogen analysis of soils by automated combustion techniques. Communications in Soil Science and Plant Analysis, 22, 843-850.

Yi, R., Yang, X., Zhou, R., Li, J., Yu, H., Hao, Z., Guo, L., Li, X., Lu, Y. \& Zeng, X. 2018. Determination of trace available heavy metals in soil using laser-induced breakdown spectroscopy assisted with phase transformation method. Analytical chemistry, 90, 7080 7085.

Yu, K.-Q., Zhao, Y.-R., Liu, F. \& He, Y. 2016. Laser-Induced Breakdown Spectroscopy Coupled with Multivariate Chemometrics for Variety Discrimination of Soil. Scientific Reports, 6, 27574.

Zaytsev, S.M., Krylov, I.N., Popov, A.M., Zorov, N.B. \& Labutin, T.A. 2018. Accuracy enhancement of a multivariate calibration for lead determination in soils by laser induced 
breakdown spectroscopy. Spectrochimica Acta Part B: Atomic Spectroscopy, 140, 65-72.

Zorov, N.B., Popov, A.M., Zaytsev, S.M. \& Labutin, T.A. 2015. Qualitative and quantitative analysis of environmental samples by laser-induced breakdown spectrometry. Russian Chemical Reviews, 84, 1021-1050. 


\section{Figures}

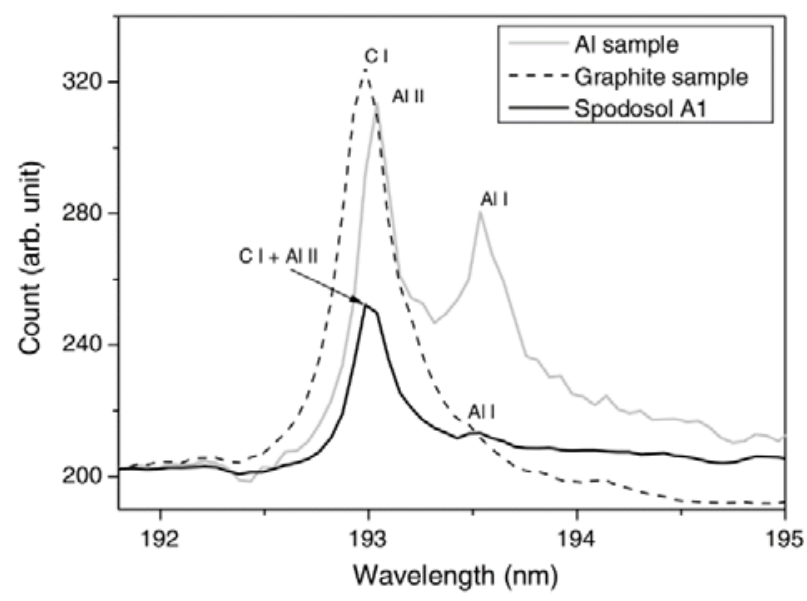

Figure 1. Emission lines of three samples: Al alloy, graphite, and Spodosol, demonstrating the overlap between Al and C lines. Reprinted with permission from the work of Nicolodelli et al. (2014).
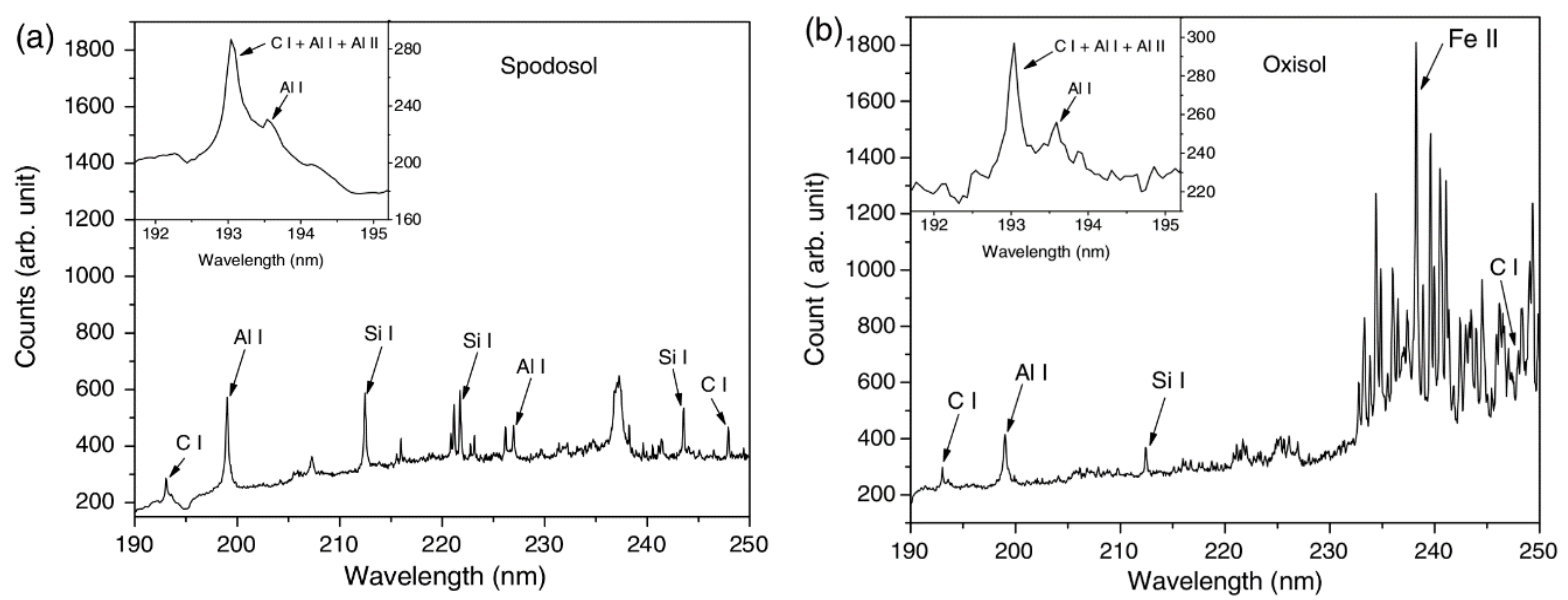

Figure 2. LIBS spectra of (a) a Spodosol, and (b) an Oxisol, showing the main emission lines in the region. Reprinted with permission from the work of Nicolodelli et al. (2014). 


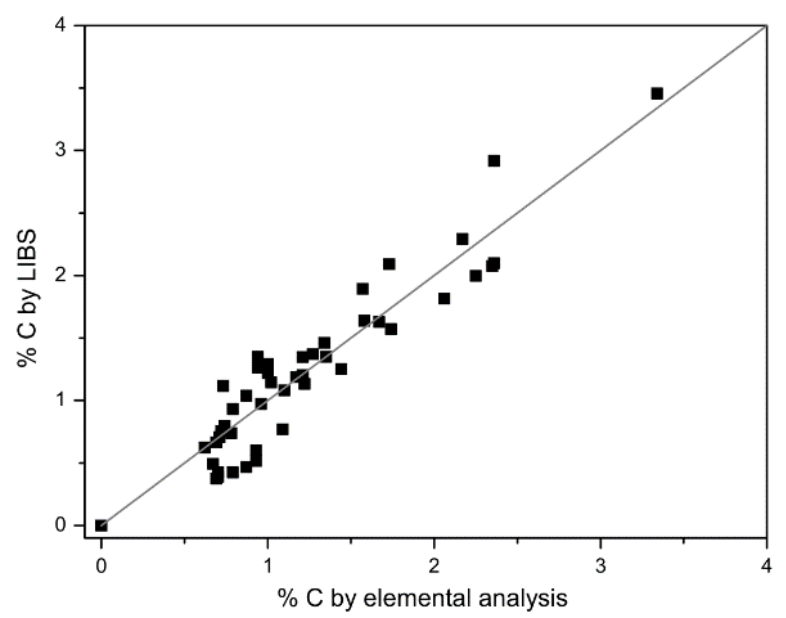

Figure 3. Validation curve for $\mathrm{C}$ concentration determined by elemental analysis and estimated by LIBS. Reprinted with permission from the work of Nicolodelli et al. (2014).

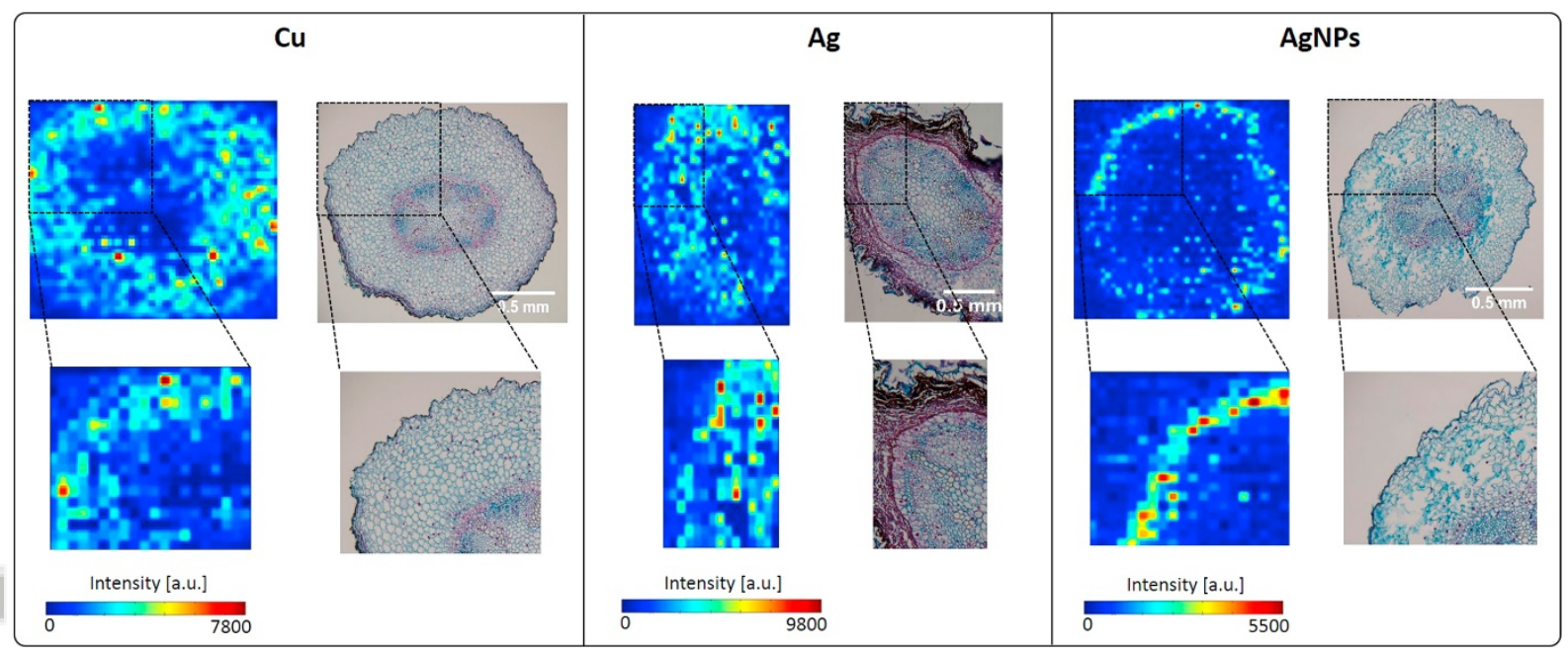

Figure 4. LIBS mapping of $\mathrm{Cu}, \mathrm{Ag}$, and silver nanoparticle (AgNPs) distributions in the cross-sections of sample roots of fava bean (Vicia faba) cultivated with solutions of CuSO4, AgNO3, and AgNPs over 7 days. Reprint with permission from the work of Krajcarová et al. (2017). 


\section{Tables}

Table 1. Emission lines of nutrients used in LIBS for soil analysis.

\begin{tabular}{ll}
\hline Nutrient & Emission lines (nm) \\
\hline Nitrogen (N) & $742.36,744.23,746.83^{*}$ \\
Phosphorus (P) & $178.3,213.61,255.32^{*}, 255.5$ \\
Potassium (K) & $404.7,766.49^{*}, 769.90$ \\
Sulphur (S) & $180.7,182.6,191.47,545.4$ \\
Magnesium (Mg) & $280.27,285.2$ \\
Calcium (Ca) & $317.9,318.1,393.37,396.8,428.3$ \\
Boron (B) & 255.14 (BO molecular fragment) \\
Copper (Cu) & $324.75^{*}, 327.4$ \\
Iron (Fe) & $274.6,274.9,404.6,406.4,407.2,489.15$ \\
Manganese (Mn) & $380.67,475.4,472.7,478.3$ \\
Zinc (Zn) & $213.86,334.59,472.2$ \\
Molybdenum (Mo) & $313.26,550.65$ \\
Chlorine (Cl) & 133.6 \\
\hline
\end{tabular}

*Emission line mostly used. 
Table 2. Limit of detection (LOD) of the reference technique and LIBS (lowest values found in the literature cited). For comparison, guideline values are also shown for toxic element contamination in soils based on Finish legislation, which is a good approximation of the mean values of other European country systems. Adapted with permission from the work of Tóth et al. (2016).

\begin{tabular}{lcccc}
\hline Element (symbol) & $\begin{array}{c}\text { LOD } \\
\left(\mathbf{m g ~ k g}^{-1}\right)\end{array}$ & $\begin{array}{c}\text { LIBS LOD } \\
\left(\mathbf{m g ~ k}^{-1}\right)\end{array}$ & $\begin{array}{c}\text { Lower guideline value } \\
\left(\mathbf{m g ~ k g}^{-1}\right)\end{array}$ & $\begin{array}{c}\text { Higher guideline value } \\
\left(\mathbf{m g ~ k g}^{-1}\right)\end{array}$ \\
\hline Antimony (Sb) (p) & 2 & $0.221^{1}$ & $10(\mathrm{~h})$ & 50 \\
Arsenic (As) (p) & 5 & $3.3^{2}$ & 50 & 5 \\
Mercury (Hg) & 0.5 & $0.7^{3}$ & 2 & 20 \\
Cadmium (Cd) & 1 & $0.067^{4}$ & 10 & 250 \\
Cobalt (Co) (p) & 20 & $1^{5}$ & 100 & 300 \\
Chrome (Cr) & 100 & $0.8^{3}$ & 200 & 200 \\
Copper (Cu) & 100 & $0.6^{6}$ & 150 & 750 \\
Lead (Pb) & 60 & $0.94^{4}$ & $200(\mathrm{~h})$ & 150 \\
Nickel (Ni) & 50 & $6.2^{7}$ & 100 & 400 \\
Zinc (Zn) & 100 & $7^{4}$ & 250 & 150 \\
Vanadium (V) & 200 & $1^{8}$ & & 250 \\
\hline
\end{tabular}

All guideline values have been defined based on ecological risks, except the lower guideline value for antimony and lead, marked as (h). Elements marked with (p) present a higher risk than normal for groundwater contamination below the lower guideline value.

1. LIBS assisted with laser-induced fluorescence for Sb emission line (Gao et al., 2018)

2. LIBS operating with Nd:YAG laser at $1064 \mathrm{~nm}, 450 \mathrm{~mJ}$ and 5-7 ns per pulse (Hilbk-Kortenbruck et al., 2001);

3. Coarse metal powder-Assisted pulse $\mathrm{CO}_{2}$ LIBS (Khumaeni et al., 2017);

4. LIBS assisted with phase transformation method (solid-liquid-solid) (Yi et al., 2018);

5. LIBS assisted with laser-induced fluorescence for Co emission lines (Gornushkin et al., 1997);

6. LIBS operating with Nd:YAG laser at $355 \mathrm{~nm}, 21 \mathrm{~mJ}$ per pulse (Popov et al., 2014);

7. LIBS using hemispherical plasma spatial confinement (Meng et al., 2015); 
8. LIBS and plasma spatial confinement (Zorov et al., 2010).

Table 3. Emission lines of toxic elements used in laser-induced breakdown spectroscopy (LIBS) for soil analysis.

\begin{tabular}{ll}
\hline Element & Emission lines (nm) \\
\hline Antimony (Sb) & 252.85 \\
Arsenic (As) & $188.98,200.34,228.81,234.98^{*}$ \\
Mercury (Hg) & $194.15,435.83^{*}, 546.07$ \\
Cadmium (Cd) & $214.44,226.50,228.80^{*}, 340.37,346.62,479.99,508.58$, \\
Cobalt (Co) & 399.53 \\
Chrome (Cr) & $336.80,337.92,340.33,340.87,342.27,343.36,357.87,359.35,360.53,425.43^{*}$, \\
& $427.48,428.97,433.94,434.45,437.42,475.61,478.93,479.3,480.10,520.60$ \\
Copper (Cu) & $282.43,324.75^{*}, 327.4,510.6,515.3,521.8$ \\
Lead (Pb) & $405.78^{*}$ \\
Nickel (Ni) & $229.00,231.10,231.60,231.72,232.00,333.06,336.96,341.48,344.62,345.84$, \\
& $346.17,346.75,348.59,349.30,352.45,357.19,359.77,361.94,508.05,510.00$, \\
Zinc (Zn) & 511.54 \\
Vanadium (V) & $413.86,334.50,472.22 *, 481.05$, \\
Emission line mostly used.
\end{tabular}

